\title{
Morfologia da língua e características das papilas linguais de Cuniculus paca (Rodentia: Cuniculidae)
}

\author{
Mariana Casteleti Beraldo-Massoli ${ }^{1}$ \\ Priscilla Rosa Queiroz Ribeiro ${ }^{2}$ \\ Lucélia Gonçalves Vieira ${ }^{2}$ \\ Lorena Tannús Menezes ${ }^{2}$ \\ Mariana Oliveira Lima ${ }^{2}$ \\ Rogério Rodrigues de Souza ${ }^{2}$ \\ Márcia Rita Fernandes Machado ${ }^{1}$ \\ André Luiz Quagliatto Santos ${ }^{2}$

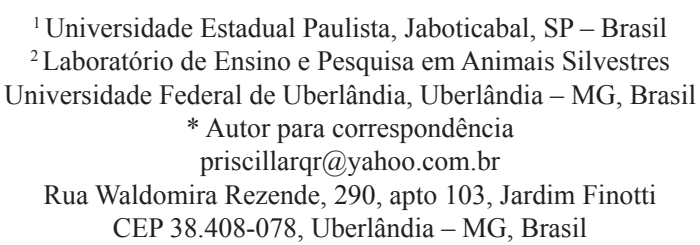

Submetido em 18/03/2013

Aceito para publicação em 02/09/2013

\section{Resumo}

Este artigo descreve a morfologia da língua, seus músculos extrínsecos e as características das papilas linguais de Cuniculus paca. Foram utilizados quinze espécimes provenientes do Setor de Animais Silvestres da Universidade Estadual Paulista (UNESP). Nessa espécie, a língua se divide em três regiões: raiz, corpo e ápice. Este último é delimitado pelo frênulo lingual, que possui aspecto de membrana fibrosa. Identificou-se também um sulco mediano e uma proeminência em sua superfície dorsal. Os músculos extrínsecos da língua são o estiloglosso, hioglosso, genioglosso, gêniohioide e milohioide, estes dois últimos inseridos no aparelho hioide. Quanto à presença de papilas linguais, em todos os espécimes se observou cinco tipos de papilas: filiforme, fungiforme, valada, folheada e cônica. As papilas filiformes distribuem-se por toda a superfície do ápice e corpo da língua. São inclinadas caudalmente por todo o corpo, até que se modificam na região da raiz e formam as papilas cônicas. As papilas fungiformes distribuem-se em grande quantidade no ápice lingual, entre as papilas filiformes. Esse tipo de papila possui formato semelhante a cogumelos. Apenas duas papilas valadas estão localizadas na porção caudal da raiz lingual, possuem formato ovalado e estão envolvidas por um sulco profundo. As papilas folheadas apresentam-se em sulcos ou ranhuras paralelas localizadas na porção lateral da língua, entre as papilas valadas e a metade da proeminência intermolar. Na raiz, corpo e ápice da língua foi observado epitélio do tipo estratificado pavimentoso queratinizado, que reveste tanto as papilas linguais como a superfície entre elas.

Palavras-chave: Anatomia; Mamíferos; Músculos extrínsecos da língua 


\section{Abstract}

Morphology of the tongue and characteristics of lingual papillae in Cuniculus paca (Rodentia: Cuniculidae). This paper describes the morphology of the tongue, its extrinsic muscles, and the characteristics of lingual papillae in Cuniculus paca. We used fifteen specimens from the Wild Animals Sector of Universidade Estadual Paulista (UNESP). In this species, the tongue is divided into three regions: root, body, and apex. The latter is delimited by the lingual frenum, which has the aspect of fibrous membrane. We also identified a median groove and a prominence on its dorsal surface. The extrinsic tongue muscles are the styloglossus, hyoglossus, genioglossus, geniohyoid, and milohyoid, the latter two are inserted into the hyoid apparatus. As for the presence of lingual papillae, we observed five papillae types in all specimens: filiform, fungiform, vallate, foliate, and conic. The filiform papillae are distributed throughout the apex surface and tongue body. They are caudally inclined throughout the body, until they are modified in the root region and form the conic papillae. The fungiform papillae are distributed in a large amount on the lingual apex, between the filiform papillae. This papilla type has a mushroom-like shape. Only two vallate papillae are located in the caudal portion of the lingual root, and they have an oval shape and are surrounded by a deep groove. The foliate papillae are observed in parallel grooves or slots located in the lateral portion of the tongue, between the vallate papillae and half of the intermolar prominence. In the tongue root, body, and apex we observed keratinized squamous stratified epithelium lining both the lingual papillae and the surface between them.

Key words: Anatomy; Extrinsic tongue muscles; Mammals

\section{Introdução}

Depois da capivara (Hydrochoerus hydrochaeris), a paca (Cuniculus paca) é considerada o segundo maior mamífero roedor da região neotropical, que compreende as Américas Central e do Sul, desde o México até o Paraguai, com tempo médio de sobrevida de 16 anos. $\mathrm{O}$ animal adapta-se bem a ambientes variados, porém prefere zonas cobertas com vegetação alta, próximas a rios ou riachos, onde constroi sua toca (MATAMOROS, 1982; DEUTSCH; PUGLIA, 1988; SAINSBURY, 2003). A dieta é composta de raízes, folhas, frutos, cana-de-açúcar e mandioca, sendo importante na difusão de sementes (VIEIRA, 1953; MATAMOROS, 1982; SAINSBURY, 2003).

Como parte do sistema digestório, a língua dotouse de características funcionalmente especializadas, as quais a tornam um órgão importante na adaptação das espécies durante o processo evolutivo dos mamíferos (KARDONG, 2010). Sonntag (1920) publicou uma série de estudos procurando demonstrar a importância desse órgão na filogenia. Seu trabalho pode ser considerado ponto de referência para pesquisas sobre a anatomia da língua das diferentes espécies.

Segundo Kilinc et al. (2010), a estrutura e distribuição das papilas linguais se constituem em importantes aspectos no estudo morfológico da língua dos animais. Estudos da superfície da língua de mamíferos têm demonstrado vários tipos de papilas (BENETTI et al., 2009). Além da espécie, essas variações estão relacionadas com o tipo de alimentação e a adaptação do animal as condições ambientais (KILINC et al., 2010). Fatores como a mecânica da mastigação e a forma de passagem do alimento aos segmentos subsequentes do trato digestório também afetam a estrutura do epitélio lingual (KARDONG, 2010).

A mucosa da língua apresenta um sistema altamente diferenciado de papilas, com funções mecânicas e gustativas (KONIG; LIEBICH, 2004). Nos mamíferos domésticos, as papilas linguais distinguem-se quanto à sua morfologia em papilas filiformes, fungiformes, valadas e folheadas. Notavelmente, animais herbívoros possuem papilas filiformes, fungiformes e valadas, mas lhes faltam as papilas folheadas (ZHENG; KOBAYASHI, 2006). As papilas filiformes, cônicas e lentiformes possuem funções mecânicas, enquanto que as fungiformes, valadas e folheadas possuem função gustativa (KONIG; LIEBICH, 2004).

A paca tem sido alvo de numerosos estudos anatômicos, como por exemplo, descrição do arco aórtico (OLIVEIRA et al., 2001); análise morfológica da placenta (BONATELLI et al., 2001); descrição 
anátomo-radiográfica da arcada dentária (OLIVEIRA et al., 2006); topografia do cone medular (SCAVONE et al., 2007) e origem e distribuição dos nervos periféricos do plexo braquial (SCAVONE et al., 2008). No entanto, ainda há escassez de estudos sobre a anatomia do sistema digestório, inclusive das estruturas linguais.

Para outros mamíferos existem vários trabalhos que abordam as características morfológicas da língua. Isto tem sido demonstrado nas contribuições de Boshell et al. (1982), em felinos; Chamorro et al. (1987) e De Paz Cabello et al. (1988), em equinos e ruminantes; Kobayashi et al. (1989), no estudo de aspectos estruturais e ultraestruturais das papilas linguais de roedores; Iwasaki e Miyata (1989), em caninos; Agungpriyono et al. (1995), em ruminantes selvagens; Kobayashi et al. (2003), em coala; Watanabe et al. (2009), em queixada; e Benetti et al. (2009), em bicho-preguiça. Entretanto, a musculatura da língua e o epitélio da mucosa lingual da paca ainda não foram estudados. Assim, o objetivo do presente trabalho foi realizar uma descrição conjunta da morfologia da língua, suas estruturas musculares e papilas linguais desta espécie.

\section{Material e Métodos}

Foram utilizadas 15 línguas de pacas adultas, machos e fêmeas, pertencentes ao acervo do Laboratório de Anatomia da Faculdade de Ciências Agrárias e Veterinárias, UNESP do Campus de Jaboticabal, São Paulo, onde foram fixados mediante injeção de solução aquosa de formaldeído a 3,7\%, na artéria carótida comum esquerda, e posteriormente mergulhados em cubas contendo a mesma solução, por no mínimo $72 \mathrm{~h}$.

Após a fixação dessas peças, procedeu-se a dissecação mediante incisão e rebatimento da pele na região da maxila e mandíbula, para visualização dos músculos relacionados à língua. Posteriormente, a desarticulação da mandíbula foi realizada para a descrição da inserção da língua no assoalho da cavidade oral, com intuito de elucidar sua topografia. Em sequência, a língua foi individualizada para o estudo de sua morfologia. Em cada espécime, foi identificado o tipo, a forma e a distribuição das papilas linguais. Essas observações foram efetuadas com o auxílio de microscópio estereoscópio SQF-E $\left(\right.$ Coleman $\left.{ }^{\circledR}\right)$ com aumentos de sete a 25 vezes. Para documentação destas estruturas, fotografias e desenho esquemático foram obtidos.

Para a identificação das características microscópicas da língua foram colhidos fragmentos do ápice, corpo e raiz. Estes fragmentos foram fixados em Bouin, e posteriormente incluídos em Paraplast, segundo a rotina histológica convencional. Os blocos obtidos foram cortados em micrótomo automático (Leica, RM2155). Os cortes, corados em Hematoxilina/ Eosina (HE), Ácido Periódico de Schiff (P.A.S.), Tricrômico de Masson e Heidenhain Schleicher (HS), foram montados e analisados. As fotomicrografias para a documentação de algumas preparações foram realizadas em microscópio Olympus BX50.

\section{Resultados}

As línguas das pacas apresentam um formato alongado com um ápice arredondado. Três regiões bem delimitadas são distinguidas na língua, uma mais caudal, a raiz que contém as papilas valadas; o corpo, região entre a raiz e o ápice, este último delimitado pelo frênulo lingual, característico por se apresentar com aspecto de uma membrana fibrosa. O terço cranial da língua é demarcado por um sulco mediano e no terço caudal destaca-se uma leve proeminência em sua superfície dorsal (Figura 1).

Os músculos extrínsecos da língua dispõemse lateromedialmente e apresentam-se com simetria bilateral. Identificaram-se os seguintes músculos: estiloglosso, hioglosso e genioglosso, gêniohioide e milohioide, estes dois últimos situam-se ventralmente entre os corpos da mandíbula (Figuras 2A, 2B e 2C).

Os músculos milohioide e o gêniohioide estão inseridos no aparelho hioide, este é formado pelo processo lingual, lâmina em posição rostral; pelo ceratohioide que se coloca caudalmente, paralelo à cartilagem tireoide da laringe; o epihioide ligando o ceratohioide ao estilohioide, que se caracteriza por formar uma haste membranácea que se coloca desde o epihioide até o osso temporal, onde se insere (Figuras 2B e D). 
FIGURA 1: Imagens fotográficas e desenho esquemático da língua da paca adulta, vista dorsal. Em (A), destaque para as papilas fungiformes e filiformes; (B), papilas folheadas; (C), papilas valadas; (D), papilas cônicas; (E), destaque para o formato, regiões, sulco mediano e proeminência da língua; (F), desenho esquemático. Abreviaturas: ap, ápice; va, papilas valadas; con, papilas cônicas; co, corpo; fi, papilas filiformes; fo, papilas folhadas; fu, papilas fungiformes; ra, raiz; sm, sulco mediano. Aumento: E 7x; A, B e C 30x e D 40x.
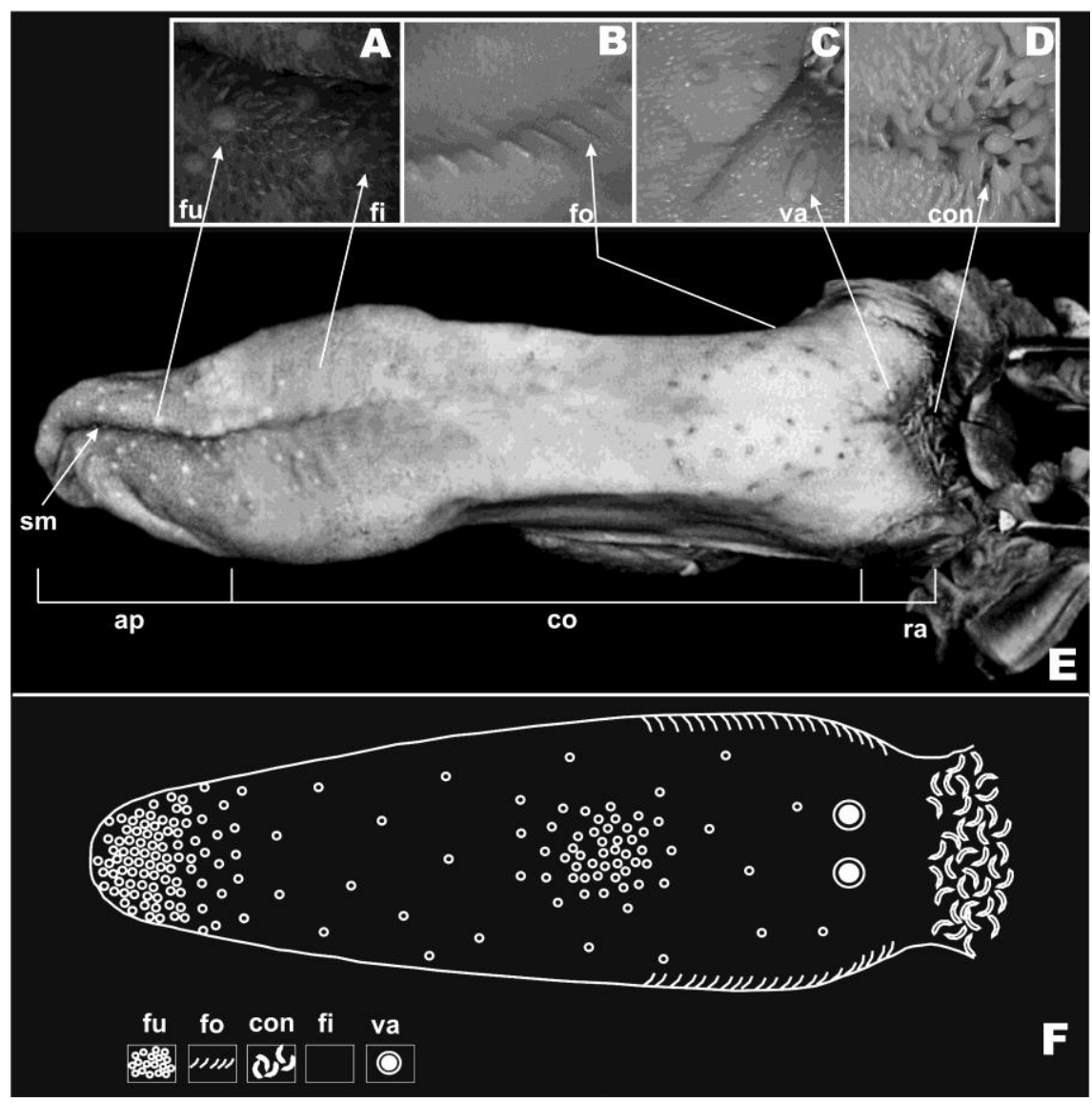

FIGURA 2: Músculos extrínsecos da língua de uma paca adulta, em vista ventral. (A), destaque para os músculos hioglosso (bola branca); genioglosso (bola preta) e estiloglosso (seta). (B e C), destaque para o músculo gêniohioide e (D), destaque para músculo milohioide. Abreviaturas: ge, gêniohioide; mi, milohioide.

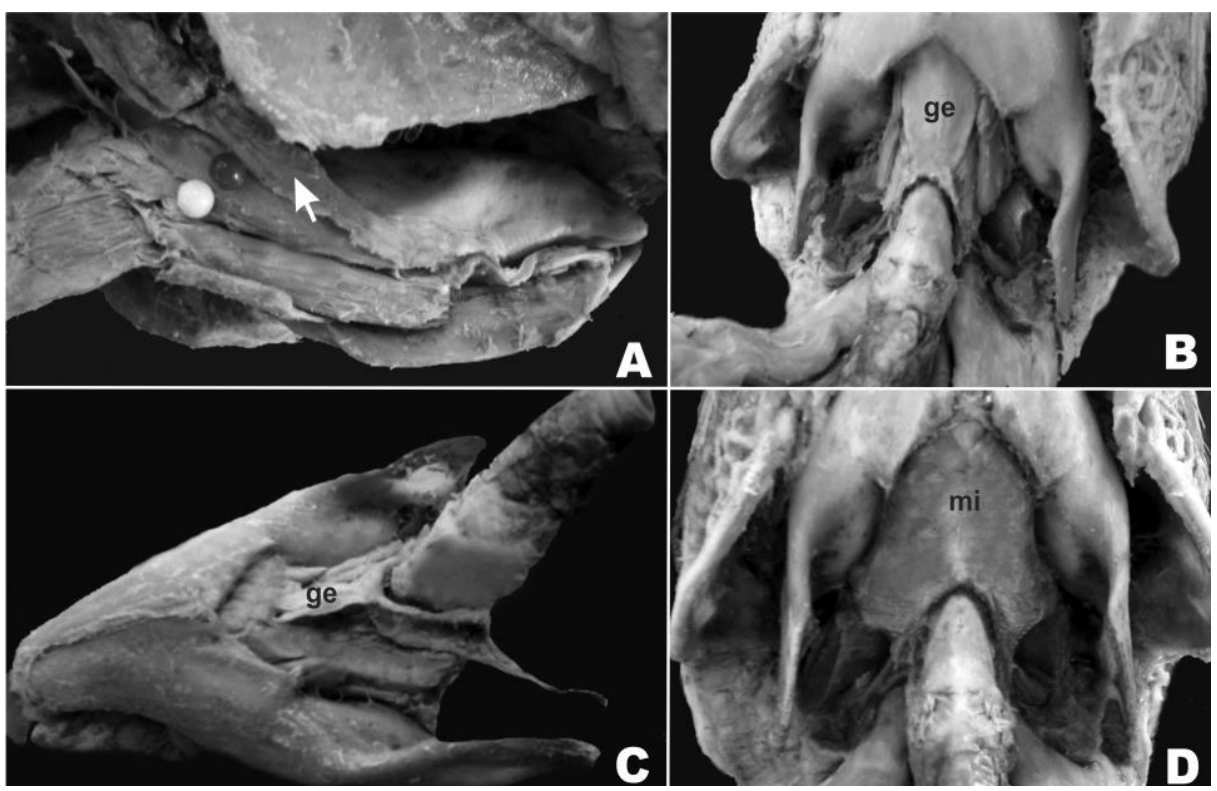


Quanto à presença de papilas linguais, em todos os espécimes analisados observou-se a presença de cinco tipos de papilas: filiforme, fungiforme, valada, folheada e cônica (Figura 1).

As papilas filiformes distribuem-se densamente por toda a superfície dorsal e lateral do ápice e corpo da língua, apresentam-se proeminentes no ápice, tornam-se inclinadas caudalmente por todo o corpo, e na região da raiz, modificam-se e formam as papilas cônicas (Figuras 1A, 1D e 1F). As papilas fungiformes encontram-se em grande quantidade no ápice lingual, se distribuem quase que equitativamente nas superfícies dorsal e lateral e na proeminência intermolar entre as papilas filiformes. No corpo lingual, a quantidade de papilas fungiformes diminui bastante. Este tipo de papila possui formato semelhante a cogumelos, redonda e convexa (Figuras 1A, 1E e 1F).

As papilas valadas estão localizadas na porção caudal da raiz lingual. A paca possui apenas duas papilas deste grupo, que se apresentam ovaladas, envolvidas por um sulco profundo e no centro há outro sulco, o sulco central, sendo este menos pronunciado (Figuras $1 \mathrm{C}$ e 1F). Caudalmente a estas papilas encontram-se as papilas cônicas. Estas se mostram com formato alongado, com base larga e ponta romba. Diferenciam-se das papilas filiformes pelo seu comprimento maior e por não possuírem projeções pontiagudas (Figuras 1D e 1F).

As papilas folheadas apresentam-se em sulcos ou ranhuras paralelas em forma de "I"; estas papilas estão localizadas na porção lateral da língua entre as papilas valadas e a metade da proeminência intermolar (Figuras 1B e $1 F)$.

Histologicamente, na raiz, corpo e ápice das línguas das pacas foi possível observar um epitélio do tipo estratificado pavimentoso queratinizado que reveste tanto as papilas linguais quanto a superfície entre elas (Figura 3A). Este epitélio se apoia em uma lâmina própria vascularizada, formada por tecido conjuntivo

FIGURA 3: Fotomicrografias do ápice da língua de paca adulta. Em (A), presença de epitélio do tipo estratificado queratinizado revestindo as papilas filiforme, fungiforme e região entre as papilas. Coloração em Hematoxilina/Eosina; (B e C), tecido conjuntivo frouxo com glândulas mucosas e serosas com seus respectivos ductos excretores da língua. Coloração em Ácido Periódico de Schiff; (D), observa-se a camada de tecido muscular estriado esquelético abaixo da lâmina própria. Coloração Heidenhain Schleicher (HS); (E), tecido adiposo entre os feixes de fibras musculares. Coloração PAS. Abreviaturas: ad, tecido adiposo; dm, ducto da glândula mucosa; ds, ducto da glândula serosa; fi, papilas filiforme; fu, papilas fungiforme; flo, fibra longitudinal; mu, mucosa; fob, fibra obliqua; rep, região entre papilas; se, serosa; tcf, tecido conjuntivo frouxo; ftr, fibra transversal. Aumento: A, 200X; BCD, 40X e E, 100X.

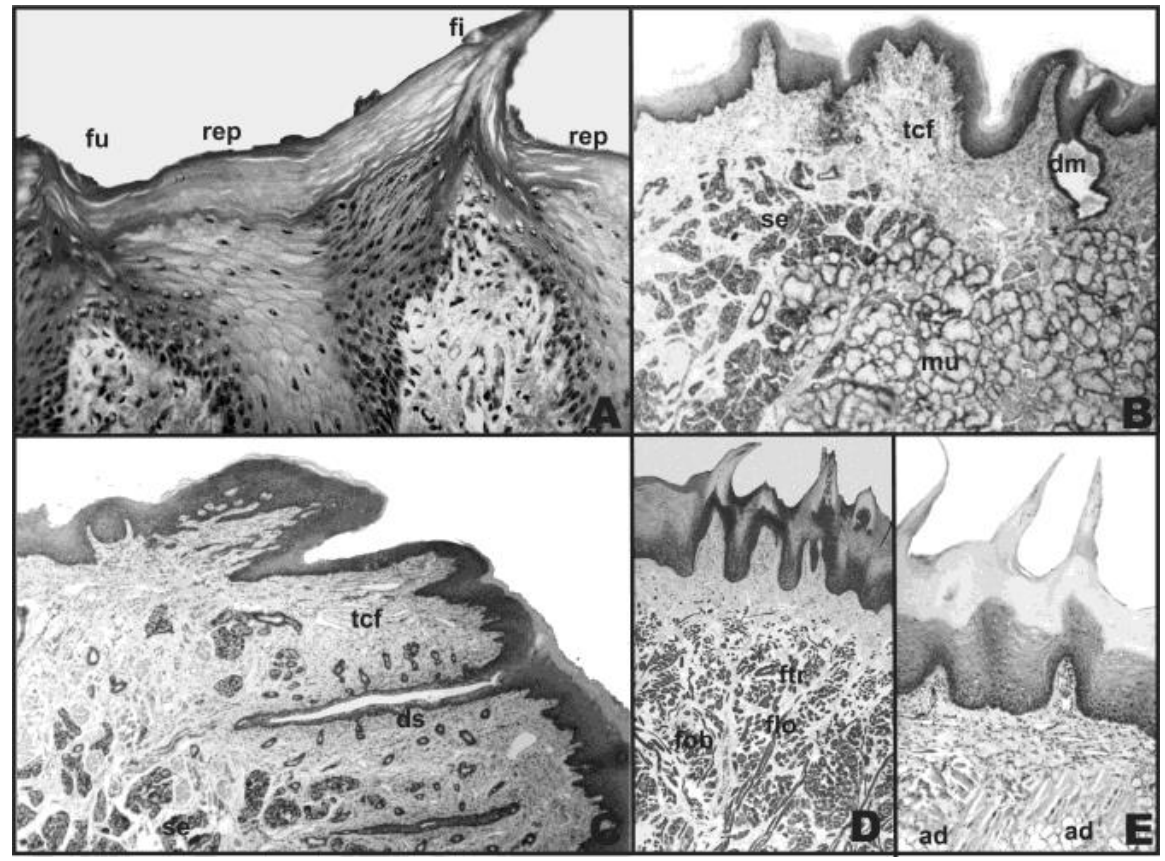


frouxo, no qual estão inseridas glândulas mucosas e serosas com seus ductos excretores (Figuras 3B e 3C). A lâmina própria, por sua vez, é contínua com uma camada de tecido muscular estriado esquelético, com fibras dispostas em direções transversal, longitudinal e oblíqua. Dessa forma, a mucosa apresenta-se fortemente aderida à massa muscular devido à penetração do tecido conjuntivo da lâmina própria, entre as fibras musculares; onde também se evidencia a presença de tecido adiposo (Figuras 3D e 3E).

Com análises utilizando microscopia de luz foi possível confirmar a presença das papilas filiformes e fungiformes em todas as porções da língua, sendo que as papilas filiformes variam em tamanho e espessura de acordo com a região (Figura 4A). No ápice da língua foi observada a presença de papilas filiformes e fungiformes em maior concentração. As papilas filiformes, comparadas às fungiformes, apresentaram-se mais pontiagudas e as papilas fungiformes, mostraram-se mais alargadas e achatadas (Figura 4B), com a presença de botões gustativos (Figura 4C).

No corpo da língua, encontraram-se papilas filiformes e fungiformes e na raiz papilas cônicas e valadas. As cônicas, embora sejam papilas filiformes modificadas, apresentam-se bem mais pontiagudas e espessas (Figura 4D). As papilas folheadas foram evidenciadas nas regiões laterais da língua. Caracterizamse pela presença de vários sulcos intercalados às mesmas, e, à semelhança das outras, revestem-se por epitélio lingual e apresentam muitos corpúsculos gustativos (Figura 4E).

\section{Discussão}

No presente estudo foi realizada a descrição morfológica da língua da paca e de seus principais músculos extrínsecos, com ênfase nas papilas linguais. Embora a presença das papilas na superfície dorsal da língua seja uma característica da espécie animal, a sua morfologia e organização, dependendo do hábito alimentar, podem apresentar diferenças significativas e merecem ser destacadas.

De acordo com Sonntag (1920), a língua dos mamíferos difere muito quanto ao seu tamanho e formato, exibindo aparência cônica, espatulada, triangular, vermiforme ou alongada com ápice afilado como na própria paca e no roedor da família Geomyidae (STANGL; PFAU, 1994). No coala, Kobayashi et al.

FIGURA 4: Fotomicrografias do corpo da língua de uma paca adulta. Em (A), papilas filiformes e fungiformes. Coloração Heidenhain Schleicher (HS); (B), papilas filiforme e fungiforme. Coloração tricrômico de Masson; (C), presença de botões gustativos na papila fungiforme. Coloração em Ácido Periódico de Schiff; (D), papilas cônicas. Coloração PAS; (E), papilas folheadas revestidas por epitélio lingual e corpúsculos gustativos. Coloração PAS. Abreviaturas: bg, botões gustativos; cg, corpúsculos gustativos; con, papilas cônicas; ep, epitélio; fi, papilas filiformes; fu, papilas fungiformes. A, 40X; BDE, 100X; C, 200X.

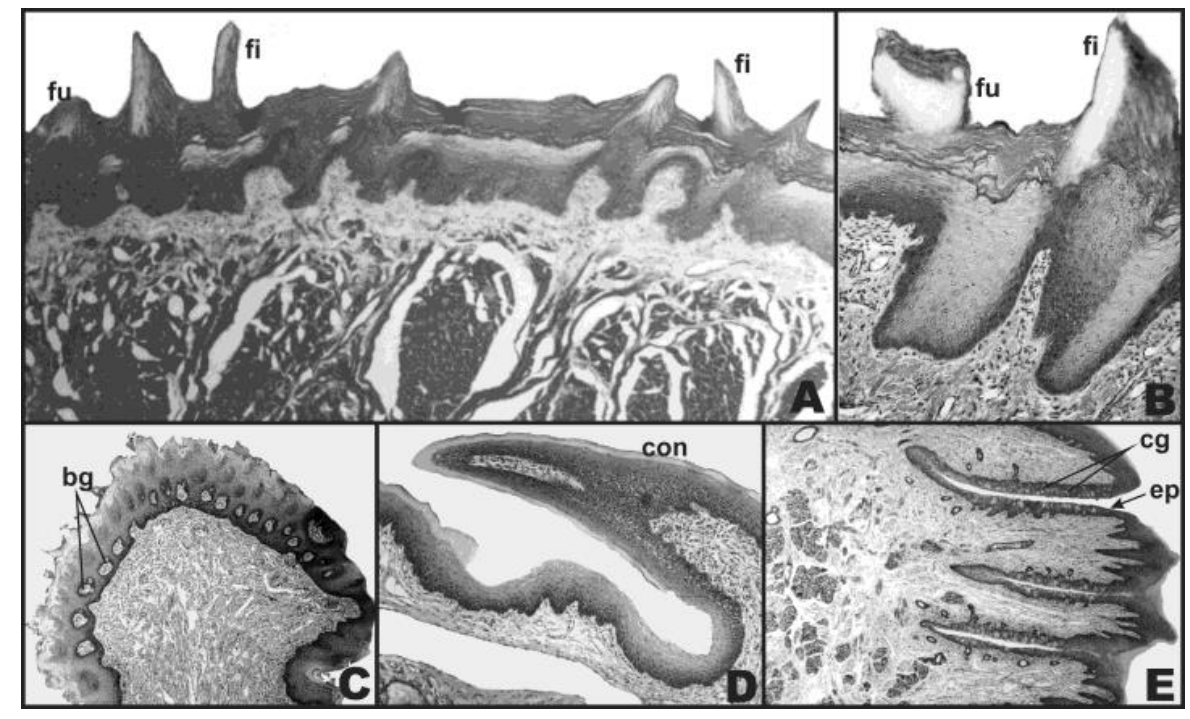


(2003) descreveram um formato diferente, segundo o autor, este animal possui uma língua alongada como na paca, porém o ápice é elíptico. Já no gambá, a língua é alongada e ovoide, assemelhando-se a uma fita com a ponta arredondada (KRAUSE; CUTTS, 1982).

$\mathrm{Na}$ língua da paca, assim como nos animais domésticos, podem ser distinguidas três regiões, raiz, corpo e ápice lingual (SCHWARZE; SCHRÖDER, 1970; FRANDSON, 1979; NICKEL et al., 1979; SISSON, 1986; DYCE et al., 1997; SCHALLER, 1999; KONIG; LIEBICH, 2004). Além disso, segundo estes autores, a face ventral da língua está fixada medialmente ao assoalho da cavidade oral pelo frênulo lingual. $\mathrm{Na}$ paca esta estrutura possui uma característica única, onde sua fixação se dá por um frênulo com aspecto membranáceo e fibroso.

$\mathrm{Na}$ superfície dorsal, foi possível constatar também um sulco terminal, na porção rostral da língua da paca tal como ocorre em Geomyidae (STANGL; PFAU, 1994). No entanto, não possuem a eminência intermolar, bem delimitada como na espécie em questão. Esta estrutura é uma característica da língua dos ornitorrincos (SONNTAG, 1920), dos coelhos (KULAWIK; GODYNICKI, 2007a; 2007b), roedores (IINO; KOBAYASHI, 1988; KITAJIMA; KOBAYASHI, 1992) e ungulados (ASAMI et al., 1995; ABD-ELNAEIN et al., 2002). Ainda quanto ao sulco terminal observado na paca e em outros roedores, este também está presente em cães, porém, é referido como sulco mediano e está relacionado à inserção de alguns músculos extrínsecos da língua, os quais, juntamente com os músculos intrínsecos, são responsáveis pelos movimentos de protrusão e retração desse órgão (SCHWARZE; SCHRÖDER, 1970; FRANDSON, 1979; NICKEL et al., 1979; SISSON, 1986; DYCE et al., 1997; KONIG; LIEBICH, 2004); acredita-se que na paca, este sulco executa a mesma função.

Ventralmente, a disposição bilateral e simétrica da musculatura extrínseca, dos músculos estiloglosso, hioglosso e genioglosso, observada na língua da paca e ainda, a ocorrência dos músculos gêniohioide e milohioide, localizados, entre os corpos da mandíbula, sugere sua relação com a grande mobilidade deste órgão. Segundo Sisson (1986), Dyce et al. (1997) e Konig e
Liebich (2004), nos animais domésticos, esta ação devese a este tipo de arquitetura muscular.

Histologicamente, o epitélio da língua da paca assemelha-se ao descrito para os animais domésticos por Dellmann e Brown (1982), Dyce et al. (1997) e Iwasaki (2002), ou seja, é do tipo estratificado pavimentoso, com vários graus de queratinização e, embora haja registro de que em muitos roedores se observa a paraqueratinização do epitélio bucal (HAMILTON; BLACKWOOD, 1974; KLEIMAN et al., 1979; PHILIPSEN et al., 1982), na paca não se verificou esta característica. O epitélio lingual da paca, assim como relatado para os animais domésticos, é mais espesso na superfície dorsal, onde possui um denso estrato córneo, e mais delgado na superfície ventral onde a queratinização pode estar ausente. A massa do músculo lingual intrínseco é composta de feixes de músculo estriado disposto longitudinalmente, transversal e verticalmente e as fibras longitudinais dorsais, bem desenvolvidas, situam-se diretamente sob a mucosa, enquanto as fibras longitudinais ventrais consistem de algumas fibras localizadas sob os feixes horizontais e transversais proeminentes (DELLMANN; BROWN, 1982; DYCE et al., 1997).

As papilas linguais da paca bem como de roedores Geomyidae, Heteromyidae, Cricetidae e Castoridae, de ruminantes selvagens, de coelhos e de gatos cobrem o dorso da língua e continuam lateralmente. O tipo estrutural mais difundido destas papilas é a filiforme. Estas estruturas minúsculas são principalmente monofilamentosas, com ponta afilada que geralmente projetam-se caudalmente (STANGL; PFAU, 1994; AGUNGPRIYONO et al., 1995; OJIMA et al., 2000; KIM et al., 2003; JACKOWIACK; GODYNICKI, 2005; SHINDO et al., 2005; NONAKA et al., 2008; FONSECA et al., 2011).

Na paca, as papilas filiformes, com função mecânica, encontram-se no ápice e no corpo da língua, assim como descrito para uma variedade de espécies de ruminantes e não ruminantes, como o panda gigante (PASTOR et al., 2008), bicho preguiça (BENETTI et al., 2009), outros roedores (KILINC et al., 2010) e cabra (FONSECA et al., 2011). O formato cônico, com a extremidade direcionada caudalmente, representa o padrão morfológico desse tipo de papila. Segundo 
Iwasaki et al. (1987), Agungpriyono et al. (1995) e Pastor et al. (2008), as papilas filiformes podem variar consideravelmente em forma e organização estrutural entre as espécies. No presente estudo, as análises histológicas revelaram diferenças na morfologia entre as papilas filiformes do ápice e do corpo, assim como relatado por Kurtul e Atalgin (2008).

Para Svejda e Sach (1975), estas papilas estão mais sujeitas a alterações morfológicas decorrentes do contato e atrito com o alimento. $\mathrm{O}$ epitélio estratificado pavimentoso queratinizado, que recobre as papilas filiformes da paca e o centro papilar formado por tecido conjuntivo derivado da lâmina própria é semelhante ao epitélio da língua de camelos (EERDUNCHAOLU et al., 2001) e cabras (FONSECA et al., 2011).

$\mathrm{Na}$ paca, as papilas fungiformes também são recobertas por um epitélio estratificado pavimentoso e contêm um ou mais corpúsculos gustativos na superfície superior. Estas papilas estão acompanhadas na sua distribuição pelas papilas filiformes, e, segundo Garcia (1989), esta última possui um número bem maior, assim como observado na paca. Estas papilas possuem um formato arredondado, achatado, com aparência de cogumelo e normalmente estão presentes em maior abundância na porção rostral da língua do que na caudal.

É interessante ressaltar que, diferente do que ocorre na paca, em carnívoros, pequenos ruminantes e suínos, os botões gustativos presentes nas papilas fungiformes de equino e bovino, são escassos (DELLMANN; BROWN, 1982; BANKS, 1992). Em geral, as papilas fungiformes observadas na língua da paca apresentam morfologia e distribuição semelhantes àquelas descritas para cabras (KUMAR et al., 1998, KURTUL; ATALGIN, 2008), cordeiros (TADJALLI; PAZHOOMAND, 2004) e também de outras espécies como o trágulo malaio (AGUNGPRIYONO et al., 1995), o bicho preguiça (BENETTI et al., 2009) e o búfalo iraniano (MAHABADY et al., 2010).

De acordo com Dellmann e Brown (1982), as papilas valadas localizam-se no dorso da raiz da língua. A presença de duas papilas valadas, com formato arredondado e presença de um sulco profundo observado nas línguas das pacas foi semelhante ao descrito em cabras, por Kumar et al. (1998) e Kurtul e Atalgin (2008), em preguiças, por Benetti et al. (2009), e em búfalo iraniano, por Mahabady et al. (2010). Já Pastor et al. (2008) descreveram a presença de múltiplas papilas secundárias separadas por sulcos de profundidades variáveis compondo a superfície das papilas valadas nos pandas gigantes. Segundo Krause e Cutts (1982), na maioria dos marsupiais e opossum há três papilas valadas arranjadas sob a forma de um triângulo equilátero, com o ápice direcionado caudalmente. Diferentemente da paca e das espécies supracitadas, as papilas valadas do cão (EVANS, 1993; DYCE et al., 1997) e do gato (OJIMA et al., 2000), distribuem-se em duas linhas convergentes formando um $\mathrm{V}$ com o ápice voltado caudalmente. Elas podem variar em número de quatro a seis no cão (SCHWARZE; SCHRÖDER, 1970; EVANS, 1993; DYCE et al., 1997) e no gato (CROUCH, 1969) ou de quatro a oito nesse último (OJIMA et al., 2000).

As papilas valadas da paca estão cobertas por um epitélio estratificado pavimentoso. O epitélio, no lado papilar do sulco, contém muitos corpúsculos gustativos; profundamente ao sulco situam-se grupos de glândulas serosas cujos ductos se abrem em vários níveis no sulco. Glândulas mucosas também podem ser encontradas por baixo das papilas, mas seus produtos de secreção são descarregados sobre a superfície da língua, estas informações estão de acordo com os relatos de Dellmann e Brown (1982).

As papilas cônicas vistas na paca estão localizadas na raiz da língua, estas nada mais são que papilas filiformes modificadas, da mesma forma que ocorre em cães, gatos e suínos (DELLMANN; BROWN, 1982; BANKS, 1992). Segundo Kobayashi et al. (2003), estas papilas em coalas se distribuem na margem caudolateral. O formato alongado, com base larga e ponta romba foi também relatado por Chamorro et al. (1987), em gatos e coelhos, Kumar et al. (1998) e Fonseca et al. (2011), em cabras. Diferente da paca, nos gatos as papilas cônicas estão em toda a superfície dorsal da língua. Elas conferem à língua seu caráter típico rugoso e áspero (GETTY, 1986).

Na paca, foi observada a presença de várias papilas folheadas, como pregas paralelas da mucosa lingual localizadas na borda lateral imediatamente rostral ao 
arco palatoglosso. Estas pregas são separadas por sulcos intercalados e são cobertas por epitélio estratificado pavimentoso contendo corpúsculos gustativos. Estas observações também foram relatadas por Fish, Manole e Richtter (1944) em ratos noruegueses. Nos primatas (KOBAYASHI et al., 2004; BURITY et al., 2009), as papilas folheadas são muito desenvolvidas e com muitos botões gustativos, já nos cães, gatos e suínos (BOSHELL et al., 1982; OJIMA, 2001; KUMAR; BATE, 2004) apresentam saliências lineares sem função paladar nenhuma, pois não apresentam botões gustativos.

A partir dos resultados, foi possível concluir que a língua da paca possui formato alongado com um ápice arredondado e é formada por três regiões bem delimitadas, a raiz, o corpo e o ápice. Os músculos extrínsecos da língua são o estiloglosso, hioglosso, genioglosso, gêniohioide e milohioide. Observou-se a presença de cinco tipos de papilas: filiforme, fungiforme, valada, folheada e cônica.

\section{Agradecimentos}

À Fundação de Amparo à Pesquisa do Estado de São Paulo (FAPESP), pelo financiamento da pesquisa.

\section{Referências}

ABD-ELNAEIM, M. M. M.; ZAYED, A. E.; LEISER, R. Morphological characteristics of the tongue and its papillae in the donkey (Equus asinus): a light and scanning electron microscopical study. Annals of Anatomy, Jena, v. 184, p. 473-480, 2002.

AGUNGPRIYONO, S.; YAMADA, J.; KITAMURA, J.; NISA, C.; SIGIT, K.; YAMAMOTO, Y. Morphology of the dorsal lingual in the lesser mouse deer Tragulus javaicus. Journal of Anatomy, London, v. 187, p. 635-640, 1995.

ASAMI, Y.; ASAMI, T.; KOBAYASHI, K. Light microscopic and scanning microscopic studies on the lingual papillae and stereo structure of their connective tissue cores in cattle. Odontology, Tokyo, v. 82, p. 1223-1244, 1995.

BANKS, W. J. Histologia veterinária aplicada. 2. ed. São Paulo: Manole, 1992. 629 p.

BENETTI, E. J.; PICOLI, L. C.; GUIMARAES, J. P.; MOTOYAMA, A. A., MIGLINO, M. A.; WATANABE, L. S. Characteristics of filiform, fungiform and vallate papillae and surface of interface epithelium-connective tissue of the maned sloth tongue mucosa (Bradypus torquatus, Iliger, 1811): light and scanning electron microscopy study. Anatomia, Histologia, Embryologia, Berlin, v. 38, p. 42-48, 2009.
BONATELLI, M.; MACHADO, M. R. F.; CRUZ, C.; MIGLINO M. A. Análise morfológica da placenta da paca (Agouti paca, Linnaeus, 1766). Estudo ao microscópio de luz e à microscopia de transmissão. Brazilian Journal of Veterinary Research and Animal Science, São Paulo, v. 38, n. 5, p. 224-228, 2001.

BOSHELL, J. K.; WILBORN, W. H.; SINGH, B. B. Filiform papillae of cat tongue. Acta Anatomica, Basel, v. 114, p. 97-105, 1982.

BURITY, C. H. F.; SILVA, M. R.; SOUZA, A. M.; LANCETTA, C. F. F.; MEDEIROS, M. F.; PISSINATTI, A. Scanning a electron microscopic study of the tongue in golden-headed tamaris, Leontopithecus chrysomelas (Callithrichidae: Primates). Zoologia, Curitiba, v. 26, p. 323-327, 2009.

CHAMORRO, C. A.; SANDOVAL, J.; FERNANDEZ, J. G.; FERNANDEZ, M.; PAZ, P. Estudio comparado de las papilas linguales del gato (Felis catus) y del conejo (Oryctolagus cuniculus) mediante el microscopio electronico de barrido. Anatomia, Histologia, Embryologia, Berlin, v. 16, p. 37-47, 1987.

CROUCH, J. E. Text-atlas of cat anatomy. Philadelphia: Lea e Febiger, $1969.78 \mathrm{p}$.

DE PAZ CABELlO, P.; CHAMORRO, C. A.; SANDOVAL, J.; FERNADEZ, F. Comparative scanning electron-microscopic study of the lingual papillae in two species of domestic mammals (Equus caballus and Bostaurus). Acta Anatomica, Basel, v. 132, p. 120 123, 1988.

DELLMANN, H. D.; BROWN, E. M. Histologia veterinária. Rio de Janeiro: Guanabara Koogan, 1982. 614 p.

DEUTSCH, L. A.; PUGLIA, L. R. R. Os animais silvestres: proteção, doenças e manejo. Rio de Janeiro: Globo, 1988. 191 p.

DYCE, K. M.; SACK, W. O.; WEISING, C. J. G. Tratado de anatomia veterinária. 2 ed. Rio de Janeiro: Guanabara Koogan, $1997.872 \mathrm{p}$.

EERDUNCHAOLU, A.; TAKEHANA, K.; YAMAMOTO, E.; KOBAYASHI, A.; CAO, G.; BAIYIN UEDA, H.; TANGKAWATTANA, P. Characteristics of dorsal lingual papillae of the Bactrian camel (Camelus bactrianus). Anatomia, Histologia, Embryologia, Berlin, v. 30, p. 147-151, 2001.

EVANS, H. E. Miller's anatomy of the dog. 3 ed. Philadelphia: W. B. Saunders, 1993. 1113 p.

FISH, H. S.; MANOLE, P. D.; RICHTTER, C. P. The anatomy of the tongue of the domestic Norway rat. The skin of yhe tongue: The various papillae: Their number and distribution. Anatomical Record, Hoboken, v. 89, p. 429-440, 1944

FONSECA, E. T.; OLIVEIRA, C. M.; FRANCIOLLI, A. L. R.; MIGINO, M. A. Características das papilas o dorso da língua de cabras (Capra hircus): estudo por de microscopia eletrônica de varredura e luz. Pesquisa Veterinária Brasileira, Rio de Janeiro, v. 31, supl. 1, p. 67-73, 2011.

FRANDSON, R. D. Anatomia e fisiologia dos animais domésticos. 5. ed. Rio de Janeiro: Guanabara Koogan, 1979. 468 p. GARCIA, G. C. Histological and histochemical studies of the digestive tract of the agouti (Dasyprocta rubrata). Veterinary Tropical, Maracay, v. 14, p. 54-55, 1989.

GETTY, R. Anatomia dos animais domésticos. Vol. 1. 5. ed. Rio de Janeiro: Interamericana, 1986. 1134 p. 
HAMILTON, A. I.; BLACKWOOD, H. J. Cell renewal of oral mucosal epithelium of the rat. Journal of Anatomy, London, v. 117, n. 2, p. 313-327, 1974.

IINO, T.; KOBAYASHI, K. Morphological studies on the lingual papillae and their connective tissue papillae of rat. Odontology, Tokyo, v. 75, p. 1039-1060, 1988.

IWASAKI, S. Evolution of the structure and function of the vertebrate tongue. Journal of Anatomy, London, v. 201, p. 1-13, 2002.

IWASAKI, S.; MIYATA, K. Fine structure of the filiform papillae of beagle dogs. Journal of Morphology, New York, v. 201, p. 235242, 1989.

IWASAKI, S.; MIYATA, K.; KOBAYASHI, K. Comparative studies of the dorsal surface of the tongue in the three mammalian species by scanning electron microscopy. Acta Anatomica, Basel, v. 128 , p. 140-146, 1987.

JACKOWIAK, H.; GODYNICKI, S. The distribution and structure of the lingual papillae on the tongue of the bank vole Clethrionomys glareolus. Folia Morphological, Prague, v. 64, p. 326-333, 2005.

KARDONG, K. L. Vertebrados: anatomia comparada, função e evolução. São Paulo: Rocca, 2010. 928 p.

KILINC, M.; ERDOGAN, S.; KETANI, S.; KETANI, M. A. Morphological study by scanning electron microscopy of the lingual papillae in the middle east blind mole rat (Spalax ehrenbergi, Nehring, 1898). Anatomia, Histologia, Embryologia, Berlin, v. 39, p. 509-515, 2010.

KIM, J. Y.; MOCHIZUKI, A. T.; AKITA, B. Q.; JUNGA, H. S. Morphological evidence of the importance of epithelial tissue during mouse tongue development. Experimental Cell Research, New York, v. 290, p. 217-226, 2003.

KITAJIMA, K.; KOBAYASHI, K. Light and electron microscopic studies on the lingual papillae and their connective tissue cores in hamster. Journal of Oral Biology, Tokyo, v. 34, p. 503-530, 1992. KLEIMAN, D. G.; EISENBERG, J. F.; MALIAK, E. Reproductive parameters and productivity of caviomorphy and rodents. In: ESENBERG, J. F. (Ed.). Vertebrate ecology in the Northern Neotropics. Washington: Smithsonian Institution, 1979. p. 173183.

KOBAYASHI, K; KUMAKURA, M.; YOSHIMURA, K.; NONAKA, K.; MURAYAMA, T.; HENNEBERG, M. Comparative morphological study of the lingual papillae and their connective tissue cores of the Koala. Anatomia, Histologia, Embryologia, Berlin, v. 206, p. 247-254, 2003.

KOBAYASHI, K.; KUMAKURA, M.; YOSHIMURA, K.; TAKAHASHI, M.; ZHENG, J. H.; KAGEYAMA, I.; KOBAYASHI, K. I.; HAMA, N. Comparative morphological studies on the stereo structure of the lingual papillae of selected primates using scanning electron microscopy. Annals of Anatomy, Jena, v.186, p. 525-530, 2004.

KOBAYASHI, K.; MIYATA, K.; TAKAHASHI, K.; IWASAKI, S. Three-dimensional architecture of the connective tissue papillae of the mouse tongue as viewed by scanning electron microscopy. Acta Anatomica, Basel, v. 64, p. 523-538, 1989.

KONIG, H. E.; LIEBICH, H. G. Anatomia dos animais domésticos: texto e atlas colorido. Órgãos e Sistemas. Vol. 2. Porto Alegre: Artmed, 2004. 788 p.
KRAUSE, W. J.; CUTTS, J. H. Morphological observations of the papillae of the opossum tongue. Acta Anatomica, Basel, v. 113, p. 159-168, 1982.

KULAWIK, M.; GODYNICKI, S. Fungiform papillae of the tongue in the rabbit (Oryctolagus cuniculus). Polish Journal Veterinary Sciences, Olsztyn, v. 10, p. 25-27, 2007a.

KULAWIK, M.; GODYNICKI, S. Vallate papillae in the domestic rabbit (Oryctolagus cuniculus $f$. domestica). Polish Journal Veterinary Sciences, Olsztyn, v. 10, p. 47-50, $2007 \mathrm{~b}$.

KUMAR, P.; KUMAR S.; SINGH, Y. Tongue papillae in goat: a scanning electron-microscopic study. Anatomia, Histolologia e Embryologia, Berlin, v. 27, p. 355-357, 1998.

KUMAR, S.; BATE, L. Scanning electron microscopy of the tongue papillae in the pig (Sus scrofa). Micro Research Techonology, Munich, v. 63, p. 253-258, 2004.

KURTUL, I.; ATALGIN, S. H. Scanning electron microscopic study on the structure of the lingual papillae of the Saanen goat. Small Ruminant Research, Amsterdam, v. 80, p. 52-56, 2008.

MAHABADY, M. K.; MORAVVATI, H.; KHAZAEIL, K. A microscopic study of lingual papillae in Iranian Buffalo (Bubalus bubalus). Asian Journal of Animal and Veterinary Advances, Faisalabad, v. 5, p. 154-161, 2010.

MATAMOROS, Y. Notas sobre la biologia del tepezcuinte, Cuniculus paca, brisson, (Rodentia: Dasyproctidae) en cautiverio. Brenesia, San Jose, v. 19/20, p. 71-82, 1982.

NICKEL, R.; SCHUMMER, A.; SEIFERLE, E. Digestive system. In: SCHUMMER, A.; NICKEL, R. (Ed.). The viscera of domestic mammals. 2 ed. Berlim-Hamburg: Verlag Paul Parey, 1979. p. 2126.

NONAKA, K.; ZHENG, J.; KOBAYASHI, K. Comparative morphological study on the lingual papillae and their connective tissue cores in rabbits. Okajimas Folia Anatomica Japonica, Tokyo, v. 85, p. 57-66, 2008.

OJIMA, K. Functional role and angioarchitectural arrangement of the filiform and fungiform papillae on the medial-dorsal surface of the beagle dog tongue. Annals of Anatomy, Jena, v. 183, p. 325$329,2001$.

OJIMA, K.; MITSUHASHI, F.; NASU, M.; SUZUKI, Y. Functional angioarchitectural comparison of the fungiform papillae of rat, rabbit, cat in scanning electron microscopic specimens. Annals of Anatomy, Jena, v. 182, p. 451-457, 2000.

OLIVEIRA, F. S.; CANOLA, J. C.; OLIVEIRA, P. T.; PÉCORA, J. D.; CAPELLI, A. Anatomoradiographic description of the teeth of pacas bred in captivity (Agouti paca, Linnaeus, 1766). Anatomia, Histolologia e Embryologia, Berlin, v. 35, p. 316-318, 2006.

OLIVEIRA, F. S.; MACHADO, M. R. F.; MIGLINO, M. A. Estudo anatômico dos ramos do arco aórtico da paca (Agouti paca, Linnaeus, 1766). Brazilian Journal of Veterinary Research and Animal Science, São Paulo, v. 38, p. 103-105, 2001.

PASTOR, J. F.; BARBOSA, M.; DE PAZ, F. J. Morphological study of the lingual papillae of the giant panda (Ailuropoda melanoleuca) by scanning electron microscopy. Journal of Anatomy, London, v. 212, p. 99-105, 2008

PHILIPSEN, H. P; CLEATON-JONES, P.; FISKER, A. V. Correlative light microscopic and scanning electron microscopic study of completely and incompletely orthokeratinized rat 
oral epithelium. Scandinavian Journal of Dental Research, Copenhagen, v. 90, p. 255-262, 1982.

SAINSBURY, A. W. Rodentia (Rodents). In: FOWLER, M. E.; MILLER, R. E. (Ed.). Zoo and wild animal medicine. 5 ed. Philadelphia: Saunders, 2003. p. 420-442.

SCAVONE, A. R. F; GUIMARÃES, G. C.; RODRIGUES, V. H. C.; SASAHARA, T. H. C.; MACHADO, M. R. F. Topografia do cone medular da paca (Agouti paca, Linnaeus, 1766). Brazilian Journal of Veterinary Research and Animal Science, São Paulo, v. 44, p. 53-57, 2007.

SCAVONE, A. R. F; MACHADO, M. R. F.; GUIMARÃES, G. C.; OLIVEIRA, F. S.; GERBASI, S. H. B.; Análise da origem e distribuição dos nervos periféricos do plexo braquial da paca (Agouti paca, Linnaeus, 1766). Ciência Animal Brasileira, Goiânia, v. 9, p. 1046-1055, 2008.

SCHALLER, O. Nomenclatura anatômica veterinária ilustrada. São Paulo: Manole, 1999. 613 p.

SCHWARZE, E.; SCHRÖDER, L. Compendia de anatomia veterinária. Zaragoza: Acribia, 1972. 315 p.

SHINDO, J.; YOSHIMURA, K.; KOBAYASHI, K. Comparative morphological study on the stereo-structure of the lingual papillae and their connective tissue cores of the American beavers. Okajimas Folia Anatomy, Tokyo, v. 84, p. 127-138, 2006.

SISSON, S. Aparelho digestório. In: GETTY, R. (Ed.). Anatomia dos animais domésticos. 5. ed. Guanabara Koogan, Rio de Janeiro, 1986. p. 105-107.
SONNTAG, C. F. The comparative anatomy of the tongues of the Mammalia. General Description of the Tongue. Proceedings of the Zoological Society of London, London, v. 90, p. 115-129, 1920.

STANGL, F. B.; PFAU, R. S. Gross morphology and distribution patterns of lingual papillae in some geomyid and heteromyid rodents. Proceedings of the Oklahoma Academy Science, Norman, v. 74, p. 25-29, 1994.

SVEJDA, J.; SKACH, M. The tree-dimensional image of the lingual papillae. Folia Morphologica, Prague, v. 22, p. 145-159, 1975.

TADJALLI, M.; PAZHOOMAND, R. Tongue papillae in lambs: a scanning electron microscopic study. Small Ruminant Research, Amsterdam, v. 54, p. 157-164, 2004.

VIEIRA, C. Roedores e lagomorfos do estado de São Paulo. Arquivos de Zoologia, São Paulo, v. 8, p. 129-160, 1953.

WATANABE, L. S.; GUIMARAES, J. P.; BOLETA, S. A.; ALMEIDA, S. R. Y.; SANTOS, R. M. M.; MIGLINO, M. A.; JUNIOR, J. R. K. Nerve endings of filliform, fungiform and vallate papillae of dorsal tongue mucosa of White-lipped peccary (Tayassu pecari): Neurohistological observations. Pesquisa Veterinária Brasileira, Rio de Janeiro, v. 29, p. 281-285, 2009.

ZHENG, J. H.; KOBAYASHI, K. Comparative morphological study on the lingual papillae and their connective tissue cores (CTC) in reeves' muntjac deer (Muntiacus reevesi). Annals of Anatomy, Jena, v. 188, p. 555-564, 2006. 